Ionizing irradiation induces apoptotic damage of salivary gland acinar cells via NADPH oxidase 1-dependent superoxide generation.

Yoshihisa Tateishi, Eri Sasabe, Eisaku Ueta, Tokio Osaki, Tetsuya Yamamoto

Department of Oral and Maxillofacial Surgery, Kochi Medical School, Kochi University,

Kohasu, Oko-cho, Nankoku-city, Kochi 783-8505, Japan

Corresponding author: Tetsuya Yamamoto

Department of Oral and Maxillofacial Surgery, Kochi Medical School, Kochi University,

Kohasu, Oko-cho, Nankoku-city, Kochi 783-8505, Japan

Tel: +81-88-880-2423, Fax: +81-88-880-2424

E-mail: yamamott@kochi-u.ac.jp

Running title: Nox1-dependent apoptosis of acinar cells 


\section{Ionizing irradiation induces apoptotic damage of salivary gland acinar cells via NADPH}

\section{oxidase 1-dependent superoxide generation.}

\section{Abstract}

Reactive oxygen species (ROS) have important roles in various physiological processes. Recently, several novel homologues of the phagocytic NADPH oxidase have been discovered and this protein family is now designated as the Nox family. We investigated the involvement of Nox family proteins in ionizing irradiation-induced ROS generation and impairment in immortalized salivary gland acinar cells (NS-SV-AC), which are radiosensitive, and immortalized ductal cells (NS-SV-DC), which are radioresistant. NS-SV-AC expressed constitutively Nox1, 2 and 4-mRNAs and NS-SV-DC expressed Nox2, 3 and 4-mRNAs. The expression levels of Nox2, 3 and 4-mRNAs were not increased after irradiation, but Nox1-mRNA was upregulated by $\gamma$-ray irradiation in NS-SV-AC. The ROS level in NS-SV-AC was increased to approximately 3 fold of the control level after 10 Gy irradiation. The increase of ROS level in NS-SV-AC was suppressed by Nox1-siRNA-transfection. The transfection of Nox2-siRNA brought only a very slight decrease of the intracellular ROS level, and Nox3- and 4-siRNAs did not influence the ROS level. In parallel with the suppression of ROS generation and Nox1-mRNA expression by Nox1-siRNA, ionizing irradiation-induced apoptosis was strongly decreased in Nox1-siRNA-transfected NS-SV-AC. There were no large differences in total SOD or 
catalase activities between NS-SV-AC and NS-SV-DC although the post-irradiation ROS level in NS-SV-AC was higher than that in NS-SV-DC. In conclusion, these results indicate that Nox1 plays a crucial role in irradiation-induced ROS generation and ROS-associated impairment of salivary gland cells and that Nox1 gene may be targeted for preservation of the salivary gland function from radiation-induced impairment.

Keywords: NADPH oxidase, Nox1, salivary gland, acinar cells, reactive oxygen species, manganese-superoxide dismutase, catalase 


\section{Introduction}

Saliva plays an essential role in the maintenance of the healthy human life. Salivary gland function is, however, easily impaired by aging, inflammation, medication, and autoimmune diseases such as Sjögren's syndrome and collagen diseases. The biological mechanism of the impairment of salivary gland function has been studied, but a detailed understanding of it has not yet been achieved. However, it has been supposed that reactive oxygen species (ROS) are involved in the impairment of salivary gland function due to aging, inflammation, drugs, and ionizing irradiation [1-4]. Not only extracellular but also intracellular ROS regulate cellular biological activities by activation and also suppression of proteins as well as by modification of DNA [5-7]. To eliminate the damage by ROS, all kinds of animal and plant cells possess ROS-scavenging and ROS-inactivation systems. These systems include antioxidant proteins such as superoxide dismutase (SOD), heme oxygenase-1, and ceruloplasmin [8-10].

ROS include singlet oxygen $\left({ }^{1} \mathrm{O}_{2}\right)$, superoxide $\left(\mathrm{O}_{2}^{-}\right)$, hydrogen peroxide $\left(\mathrm{H}_{2} \mathrm{O}_{2}\right)$, hydroxyl radical $(\mathrm{OH})$, and hypochlorous acid $(\mathrm{HClO})$. In addition to these $\mathrm{ROS}$, there are a variety of oxidized reactive lipids, which are associated with damage of blood vessel walls, perfusion-induced damage of the brain, and apoptotic degeneration of liver and kidney cells [11-14]. Of the ROS, $\mathrm{O}_{2}^{-}$is crucial in this damage because $\mathrm{O}_{2}^{-}$leads to generation of $\mathrm{OH}$ and highly reactive peroxynitrite $\left(\mathrm{ONOO}^{-}\right)$by Fenton's reaction and interaction with nitric 
oxide, respectively. In phagocytic cells, $\mathrm{O}_{2}^{-}$is produced by an NADPH oxidase complex. The oxidase complex consists of membrane-bound flavocytochrome $b_{558}$, four cytosolic regulators $\left(\mathrm{p} 67^{\text {phox }}, \mathrm{p} 47^{\text {phox }}, \mathrm{p} 40^{\text {phox }}\right)$, and a small GTPase (Rac1 or Rac2) [15]. Production of $\mathrm{O}_{2}{ }^{-}$is induced by stimuli such as bacteria, fungi, cytokines and chemicals, which trigger the translocation of cytosolic regulators to the cell membrane, resulting in their association with flavocytochrome $b_{558}[15]$.

Over the last several years, six homologues of gp91 ${ }^{\text {phox }}$, also termed Nox2, have been identified and categorized systematically as the NADPH oxidase (Nox) family [16]. The family contains seven members: Nox1 through Nox5 and the dual oxidases, Duox1 and Duox2. Nox1 is abundantly expressed in colon epithelial cells and is regarded to play a role in host defense in the colon [17]. Nox2 (gp91 $\left.{ }^{\text {phox }}\right)$ is predominantly expressed in phagocytes [15] and Nox3 exists in the inner ear of rodents, and is essential for the otoconium formation [18]. Nox4 is highly expressed in epithelial cells of renal tubules [19] and also in vascular endothelial cells [20]. Nox5 is predominantly expressed in the testis and spleen but its biological role is unknown [21]. Studies of the protein and mRNA expression and the function of the Nox family in the salivary gland have not been reported.

In this study, we hypothesized that radiation-induced hypofunction of the salivary glands would be closely associated with ROS which are generated in the salivary gland tissues, and we aimed to clarify the involvement of Nox family mRNAs and proteins in the 
ROS generation and impairment of salivary gland cells. Besed on our investigation of the expression of Nox1 to 5 proteins in immortalized salivary gland cells and studies of the induction of the Nox protein expression by $\gamma$-rays, we concluded that Nox proteins are strongly involved in radiation-induced salivary gland impairment.

\section{Materials and methods}

\section{Cell lines}

Immortalized normal salivary gland (NS-SV-AC and NS-SV-DC) cell lines were provided by Dr. M Azuma (Second Department of Oral and Maxillofacial Surgery, School of Dentistry, Tokushima University) and were maintained in keratinocyte basal medium-2 (KBM-2, Cambrex Bio Science Inc., Walkersville, MD) [22]. These cell lines were isolated based on their distinct morphology after transfection of origin-defective mutant DNA of SV40 into primary cultured human salivary gland cells. The morphological characteristics of NS-SV-AC and NS-SV-DC cells are similar to those of primary acinar and ductal cells, respectively.

\section{MTT assay}

The antiproliferative effects of radiation were determined by the 3-(4,5-dimethylthiazol-2-yl)-2,5-diphenyl- ${ }^{2} \mathrm{H}$-tetrazolium bromide (MTT) dye uptake method. NS-SV-AC and NS-SV-DC $\left(5 \times 10^{3}\right.$ cells/well) were cultured in 96-well microplates for $12 \mathrm{~h}$ 
and then irradiated at doses of 5 or $10 \mathrm{~Gy}$ using a ${ }^{137} \mathrm{Cs}$ source. After $48 \mathrm{~h}$, the cells in each well were washed with $200 \mu$ l of phosphate-buffered saline (PBS) and incubated with $100 \mu 1$ of $2 \%(w / v)$ MTT (Sigma-Aldrich Inc., St. Louis, MO) in a solution of 0.05 M Tris-HCl ( $\mathrm{pH}$ 7.6), $0.5 \mathrm{mM} \mathrm{MgCl}_{2}, 2.5 \mathrm{mM} \mathrm{CoCl}$ and $0.25 \mathrm{M}$ disodium succinate at $37{ }^{\circ} \mathrm{C}$ for $30 \mathrm{~min}$. The cells were fixed by the addition of $100 \mu \mathrm{l}$ of $4 \%(\mathrm{v} / \mathrm{v})$ formalin in $0.2 \mathrm{M}$ Tris-HCl (pH 7.6), and after a 5-min incubation at room temperature, the liquid was removed and the wells were allowed to dry. Each well was rinsed with $200 \mu \mathrm{l}$ of water and cells were solubilized by the addition of $100 \mu \mathrm{l}$ of $6.35 \%(\mathrm{v} / \mathrm{v}) 0.1 \mathrm{~N} \mathrm{NaOH}$ in DMSO. The colored formazan product was measured using a Thermo MAX micro plate reader (Molecular Devices Corp. Sunnyvale, CA) at a wavelength of $562 \mathrm{~nm}$.

\section{Reverse transcription-polymerase chain reaction (RT-PCR)}

Total RNA was isolated from approximately $90 \%$ confluent cells using an RNeasy total RNA isolation system (QIAGEN Inc., Valentia, CA). The RNA was quantitated by measuring the optical density at $260 \mathrm{~nm}$. The extracted RNA $(1 \mu \mathrm{g})$ was added to $20 \mu \mathrm{l}$ of reverse transcription buffer $(50 \mathrm{mM}$ Tris- $\mathrm{HCl}, \mathrm{pH} 8.3,50 \mathrm{mM} \mathrm{KCl}, 10 \mathrm{mM} \mathrm{MgCl}, 1 \mathrm{mM}$ EDTA, $10 \mu \mathrm{g} / \mathrm{ml}$ bovine serum albumin and $1 \mathrm{mM}$ DTT) containing $10 \mathrm{mM}$ dNTPs, $50 \mathrm{U}$ RNase inhibitor, $1 \mu \mathrm{g}$ of oligo dT primer, and $50 \mathrm{U}$ of avian myeloblastosis virus reverse transcriptase (all from Takara Biomedicals, Kyoto, Japan). This mixture was incubated at 42 ${ }^{\circ} \mathrm{C}$ for $40 \mathrm{~min}$ and heated at $99{ }^{\circ} \mathrm{C}$ for $5 \mathrm{~min}$. PCR was performed with $1 \mu \mathrm{l}$ of the cDNA 
preparation. The prepared cDNA was added to the reaction mixture containing $10 \mathrm{mM}$ Tris-HCl, pH 7.6, $50 \mathrm{mM} \mathrm{KCl,} 1.5 \mathrm{mM} \mathrm{MgCl}_{2}, 0.01 \%(\mathrm{w} / \mathrm{v})$ gelatin, $0.2 \mathrm{mM} \mathrm{dNTPs}$, both 5' and 3' primers at $0.5 \mu \mathrm{M}$, and $0.5 \mathrm{U}$ of Taq polymerase (Perkin-Elmer Corp., Hayward, CA) in a total volume of $10 \mu \mathrm{l}$. The reaction mixtures were overlaid with $50 \mu \mathrm{l}$ of mineral oil and incubated in a thermal cycler (Perkin-Elmer) for $45 \mathrm{sec}$ at $94{ }^{\circ} \mathrm{C}, 45 \mathrm{sec}$ at $60{ }^{\circ} \mathrm{C}$, and $2 \mathrm{~min}$ at $72{ }^{\circ} \mathrm{C}$ per cycle. The PCR products were electrophoresed in an agarose gel and visualized by staining with ethidium bromide. The following PCR primer sets were synthesized: Nox1; 5'-TTACTTGACCTTCAGCAACT-3' and 5'-TGTTCACACTGGATAAGAC C-3', Nox2; 5'-GGAGTTTCAAGATGCGTGGAAACTA-3' and 5'-GCCAGACTCAGAGTTTTAGATGC T-3', Nox3; 5'-ATGAACACCTCTGGGGTCAGCTGA-3' and 5'-GGATCGGAGTCACTCCC TTCGCTG-3', Nox4; 5'-CTCAGCGGAATCAATCAGCTGTG-3' and 5'-AGAGGAACACG ACAATCAGCCTTAG-3', Nox5; 5'-CTACGTGGTAGTGGGGCTGT-3' and 5'-TGGAGCAG ATGAACATGAGG-3', Duox1; 5'-GTTCTGCCCACTGTCCAGTT-3' and 5'-TTGCCCCAA ACCAGTAGCTC-3', Duox2; 5'-CTGAAACA TCCCCTCCATAC-3' and 5'-AGTAAAAGAG GCCAGTCTCA-3'.

\section{Real-time PCR}

The first-strand cDNA was analyzed with the ABI Prism 7000 sequence detection system and TaqMan reagent (PE Applied Biosystems, Foster City, CA) using the standard curve method according to the manufacturer's instructions. Equal amounts of template were 
analyzed in duplicate. VIC-labeled GAPDH (PE Applied Biosystems) was used for normalization. The TaqMan MGB probe and primer pairs were designed with ABI Primer Express software.

\section{Immunoblotting}

Cells were lysed in TNE lysis buffer (1 M Tris-HCl, $\mathrm{pH}$ 7.6, 0.5 MEDTA, 10\% Nonidet P-40). Extracted proteins $(50 \mu \mathrm{g}$ per lane) were separated by sodium dodecyl sulfate-polyacrylamide gel electrophoresis (SDS-PAGE) and transferred onto Immobilon-P membranes (Immobilon, Millipore Corporation, Bedford, MA, USA). Blocking was performed in Tris-buffered saline containing $5 \%$ skim milk powder and $0.1 \%$ Tween-20. The membranes were probed with the following diluted antibodies: Nox1 (Santa Cruz Biotechnology, Santa Cruz, CA, USA) at 1:100, Mn-SOD (Chemicon International, Temecula, CA) at 1:200 and Catalase (Calbiochem, San Diego, CA) at 1:4000 dilution. Detection was performed with an ECL system (Amersham, Piscataway, NJ, USA). Protein content was determined by using the Bradford method, with bovine serum albumin as standard.

\section{SiRNA constructions and transfection}

Nox1-5 siRNAs (Silencer Nox1-5 siRNAs) and Control siRNA (Silencer control siRNA) were obtained from PE Applied Biosystems. Cells were plated at a concentration of $2 \times 10^{5}$ cells/dish in $35 \mathrm{~mm}$ dishes. siRNAs were transfected into the cells using Oligofectamine reagents (Invitrogen, San Diego, CA, USA) according to the manufacturer's 
recommendations. After $24 \mathrm{~h}$, the cultures were irradiated.

\section{Analysis of apoptosis}

Cells exposed to $\gamma$-rays were trypsinized, washed once with complete medium and stained with propidium iodide and fluorescein isothiocyanate (FITC)-conjugated annexin V (Sigma, St. Louis, MO, USA) according to the manufacturer's instructions. The cells were then analyzed using a FACScan cytometer (using the CellQuest Program; Becton Dickinson, San Jose, CA, USA).

\section{Measurement of intracellular ROS generation}

Intracellular ROS production was measured using a fluorescent dye, dichlorofluorescein diacetate (DCFH-DA), which is converted to DCFH by esterases when it is taken up by cells. DCFH reacts with ROS to give a new highly fluorescent compound, dichlorofluorescein, which can be analyzed using a FACScan cytometer. Cells that underwent the treatment indicated were incubated with DCFH-DA $(5 \mu \mathrm{M})$ at $37^{\circ} \mathrm{C}$ for $15 \mathrm{~min}$. The cells were rinsed twice with phosphate-buffered saline (PBS) and then analyzed by using a FACScan cytometer.

\section{Assays for SOD and catalase activities}

Cells were plated at a concentration of $20 \times 10^{4}$ cells/dish in $35-\mathrm{mm}$ dishes. After 24 $\mathrm{h}$ of cultivation, the cells were irradiated (10 Gy) and then lysed in TNE lysis buffer. After centrifugation at $14,000 \mathrm{rpm}$ for $10 \mathrm{~min}$ at $4{ }^{\circ} \mathrm{C}$, the supernatants were obtained and SOD and 
catalase activities in the supernatants were assayed using an SOD Assay Kit-WST (Dojindo Molecular Technologies, Gaithersburg, MD) and an Amplex Red Catalase Assay Kit (Molecular Probes, Eugene, OR), respectively. Both activities were calibrated using a standard curve prepared with purified human SOD and catalase and they were expressed as units $(\mathrm{U}) / \mathrm{mg}$ protein.

\section{Statistical analysis}

Results are expressed as the mean \pm SEM. Differences were compared by Mann-Whitney's U-test and p values of less than 0.05 were considered statistically significant.

\section{Results}

\section{The sensitivity of NS-SV-AC and NS-SV-DC cells to $\gamma$-rays}

When NS-SV-AC cells were exposed to a single dose irradiation of 5 or $10 \mathrm{~Gy}$, their growth was inhibited to approximately $25 \%$ and $60 \%$ of the control level, respectively. In NS-SV-DC cells, the growth inhibition was approximately $20 \%$ after both 5 and 10 Gy irradiation, indicating that NS-SV-DC cells were rather non-sensitive to $\gamma$-rays compared with NS-SV-AC cells (Fig. 1A). Apoptosis in the irradiated NS-SV-AC cells was increased in a time-dependent manner and the apoptotic cell number was increased to approximately $15 \%$ of the total cells at $24 \mathrm{~h}$ after the irradiation. On the other hand, the number of apoptotic cells in the irradiated NS-SV-DC cells was only 3\% $24 \mathrm{~h}$ after the irradiation (Fig. 1B). The 
pretreatment of NS-SV-AC cells with N-acetylcystein (NAC), a ROS antioxidant, or apocynin, an NADPH oxidase inhibitor, suppressed apoptosis: the percentage of apoptotic cells among the total cells was decreased to approximately $7 \%$ and $5 \%$ at $24 \mathrm{~h}$ after 10 Gy irradiation, respectively (Fig. 1B).

The ROS levels in NS-SV-AC cells were increased during the first $6 \mathrm{~h}$ after the irradiation and were slightly decreased at $8 \mathrm{~h}$ (Fig. 1C). The increase of ROS generation was strongly suppressed by pretreatment of NC-SV-AC cells with NAC or apocynin. Compared to the ROS levels in NS-SV-AC cells, the levels in NS-SV-DC cells were markedly lower, and only a slight increase was observed at $2 \mathrm{~h}$ after the irradiation.

\section{Nox1 induction by $\gamma$-rays}

RT-PCR of Nox1-5 and Duox1 and 2 demonstrated that Nox1, 2 and 4-mRNAs were expressed in nontreated NS-SV-AC cells, and Nox2, 3 and 4-mRNA were expressed in nontreated NS-SV-DC cells (Fig. 2A). The expression levels of Nox2, 3 and 4-mRNAs were not changed by the irradiation, but Nox1-mRNA was upregulated by $\gamma$-ray irradiation in NS-SV-AC cells. In NS-SV-DC cells, elevation of Nox1-mRNA by irradiation was not observed. Real-time PCR and Western blotting for Nox1 demonstrated that Nox1-mRNA and protein were weakly expressed in NS-SV-AC cells, but were not detected in NS-SV-DC cells (Fig. 2B). Nox1-mRNA was markedly increased 30 min after the irradiation and the protein level was clearly increased in NS-SV-AC cells $6 \mathrm{~h}$ after $10 \mathrm{~Gy}$ irradiation, but the 
message was not increased in irradiated NS-SV-DC cells.

\section{Suppression of $\gamma$-rays induced ROS production and apoptosis by Nox1-siRNA}

Nox1-siRNA-transfected NS-SV-AC cells were exposed to a single dose of $10 \mathrm{~Gy}$ irradiation, and ROS production and apoptosis were examined. The ROS levels in control siRNA-transfected NS-SV-AC cells were increased to approximately 3 fold of the control levels $6 \mathrm{~h}$ after the $10 \mathrm{~Gy}$ irradiation, but the increase of ROS levels was suppressed by Nox1-siRNA-transfection to approximately 2 fold of the control level (Fig. 3A). The transfection of Nox2-siRNA caused only a minimum decrease of the ROS levels, and Nox3and 4-siRNAs did not have any influence on the ROS levels. The increase of Nox1-mRNA was strongly suppressed by the siRNA-transfection (Fig. 3B). In parallel with the suppression of ROS generation and Nox1-mRNA expression by Nox1-siRNA, radiation-induced apoptosis in Nox1-siRNA-transfected NS-SV-AC cells was decreased to approximately half of the control ( $8 \%$ versus $15 \%$ of the total cells, respectively) (Fig. 3C).

\section{Mn-SOD and catalase activities in NS-SV-AC and NS-SV-DC cells}

The expression of Mn-SOD was increased $2 \mathrm{~h}$ after $\gamma$-ray treatment in NS-SV-AC cells, but was not increased in NS-SV-DC cells (Fig. 4A). The de novo Mn-SOD activity in both kinds of cells was nearly the same, $8 \mathrm{U} / \mathrm{mg}$ protein, but whereas radiation upregulated the Mn-SOD activity in NS-SV-AC cells (the Mn-SOD activity in NS-SV-AC cells was increased to approximately 1.5 fold of the de novo level at $4 \mathrm{~h}$ after the radiation), the enzyme 
activity in NS-SV-DC cells was constant even after the radiation (Fig. 4B). On the other hand, the expression of catalase and its activity in NS-SV-DC cells were almost the same as those in NS-SV-AC cells and the catalase activity in both kinds of cells was increased to nearly equal extents by the radiation (Figs. 4C and 4D).

\section{Discussion}

The regulation of physiological and pathological reactions induced by ROS has been clarified in a variety kinds of cells, including human intact cells [11-14] and transformed cells $[23,24]$. Along with studies on ROS generation, increasing studies of the role of Nox family proteins have been reported. However, the involvement of ROS and Nox family proteins in the impairment of the salivary glands has not been sufficiently clarified. There are several causes of salivary gland dysfunction, including aging, medications, radiotherapy for cancers of the head and neck, and serious salivary gland disorders. Of these causes, physiological and iatrogenic ones are most frequently observed. The biological processes underlying physiological hypofunction of the salivary glands is not yet well understood, although the involvement of ROS is suspected [1-4]. The analysis and clarification of the mechanisms of aging-induced salivary hypofunction would bring benefit to many elderly individuals. The iatrogenic (cancer treatment-induced) hypofunction of the salivary glands has been histopathologically studied and some investigators have reported possible 
mechanisms of the impairment $[25,26]$. The involvement of ROS in the possible mechanisms has been reported [4]. Therefore, the demonstration of the involvement of ROS in the mechanism of the impairment should aid in designing the prophylaxis and treatment of physiological as well as iatrogenic hypofunction of the salivary glands.

There have been a few studies on the expression of Nox family mRNAs and proteins in different kinds of human cells [15-21], but very few studies on the expression of Nox1 to Nox5 in the salivary glands even though it has been reported that salivary gland ducts express Duox1 [27]. In the present study, NS-SV-AC and NS-SV-DC cells showed differential expression of the Nox family mRNAs. Both cell lines constitutively expressed Nox2 and Nox 4 mRNAs but did not express Nox 5 or Duox 1 or 2 mRNAs. In NS-SV-AC cells, the expression of Nox1-mRNA was strongly increased by ionizing irradiation although the basal level of Nox1-mRNA was very low in both types of cells. On the other hand, Nox3-mRNA was constitutively expressed in NS-SV-DC cells but was not expressed in NS-SV-AC cells, and its expression in NS-SV-DC cells was not increased after $\gamma$-ray exposure. Thus, the expression patterns of Nox family mRNAs differ depending on the cell line, and the above results suggest that there are different expression patterns of Nox family proteins according to the kind of cells.

The expression of Nox1-mRNA and protein in NS-SV-AC cells was upregulated by $\gamma$-rays. The human Nox 1 gene consists of 13 exons spanning approximately $31.49 \mathrm{kbp}$ of 
genomic DNA and the promoter region is approximately $4.8 \mathrm{kbp}$ upstream from the transcription site [28]. It has been reported that the transcription of Nox1 was upregulated by IL-1 $\beta$, IFN- $\gamma, 1 \alpha, 25$-dihydroxyvitamin $\mathrm{D}_{3}$ and the Toll-like receptor 5 ligand, flagellin, in large intestinal epithelial cells, and also reported that angiotensin II, prostaglandin $\mathrm{F}_{2 \alpha}$ and platelet-derived growth factor induce the expression of Nox1 in vascular smooth muscle cells [28-33]. Moreover, it has been demonstrated that mitochondrial-derived ROS positively regulate the expression of Nox1 [34], and that LPS-stimulated expression of Nox1 was profoundly suppressed in the presence of antioxidants [35]. Thus, the expression of Nox1 appears to be regulated by complex systems which differ according to the kind of cells. Because ionizing irradiation of cells causes the generation of ROS in mitochondria, $\gamma$-ray-induced upregulation of Nox1-mRNA expression in NS-SV-AC cells appears to be mediated by ROS generated in mitochondria. Further studies may clarify the pathways involved in the transcriptional activation of the Nox1 gene.

In the present study, ionizing irradiation-induced ROS generation in NS-SV-AC cells was strongly suppressed by Nox1-siRNA-transfection. However, the transfection of Nox2-siRNA caused only a minimum decrease of the ROS levels. These results indicate that Nox 1 and Nox 2 are strongly and weakly, respectively, involved in the $\gamma$-ray-induced ROS generation in NS-SV-AC cells. Nox2 forms a mutually stabilizing complex with $\mathrm{p} 22^{\text {phox }}$ and the activation of Nox 2 requires membrane translocation of $\mathrm{p} 47^{\text {phox }}, \mathrm{p} 67^{\text {phox }}$ and Rac [15]. 
Nox1 can function even in the absence of $\mathrm{p} 22^{\text {phox }}$, although $\mathrm{p} 22^{\text {phox }}$ is required for the full activity of Nox1 [36]. Furthermore, Nox1 but not Nox 2 can also be activated by the $47^{\text {phox }}$ homologue Noxo1 (Nox organizer 1) and the p6 $7^{\text {phox }}$ homologue Noxal (Nox activator 1) [37]. Therefore, the strong involvement of Nox 1 and the minimal involvement of Nox 2 in $\gamma$-ray-induced ROS generation in NS-SV-AC cells may be due to different activities of their regulatory proteins.

Neither Nox3-siRNA nor Nox4-siRNA influenced the $\gamma$-ray-induced ROS generation in NS-SV-AC cells. The present study did not examine the details of the role of Nox4. However, this result appears to indicate that Nox4 is not involved in ionizing irradiation-induced ROS generation, although it has been reported that Nox3 and Nox 4 are constitutively active and that they produce some amount of $\mathrm{O}_{2}^{-}[38,39]$.

Nox4-siRNA did not influence the $\gamma$-ray-induced ROS generation in NS-SV-AC cells. This result appears to indicate that Nox4 is not involved in ionizing irradiation-induced ROS generation. Although it has been reported that Nox3 and Nox4 are constitutively active and produce a small but significant amount of $\mathrm{O}_{2}^{-}[38,39]$, the physiological function and regulation of the expression of Nox3 and Nox4, which are expressed in only NS-SV-DC cells and in both cell lines, respectively, in the salivary gland are currently unknown.

The intracellular ROS level is regulated by the balance of ROS production and elimination. There were no large differences in total SOD or catalase activities in 
NS-SV-AC and NS-SV-DC cells, although the post-irradiated ROS level in NS-SV-AC cells was higher than that in NS-SV-DC cells. It is clinically well known that acinar cells are more sensitive to radiotherapy than ductal cells. It has been reported that radiation-induced salivary gland dysfunction is associated with the water-handling capacity of the acini and the number of acinar cells in the gland [40]. Our results supported these clinical and experimental findings. The high sensitivity of acinar cells to radiation appears to be based on the intracellular ROS level, which is determined by the ROS-generating capacity rather than the ROS-scavenging capacity.

In conclusion, this study demonstrated that human salivary gland acinar cells strongly expressed Nox1, 2 and 4, and that the knockdown of Nox1 inhibited ionizing irradiation-induced apoptosis. These results indicate that Nox1 play a pivotal role in ionizing irradiation-induced ROS generation, which is associated with salivary gland injury. Therefore, the Nox 1 gene may be targeted for preservation of the salivary gland function from impairment induced by radiotherapy and aging.

\section{References}

1. Salvolini E.; Martarelli D.; Di Giorgio R.; Mazzanti L.; Procaccini M.; Curatola G. Age-related modifications in human unstimulated whole saliva: a biochemical study. Aging (Milano). 12:445-8; 2000. 
2. Nagler R. M.; Salameh F.; Reznick A. Z.; Livshits V.; Nahir A. M. Salivary gland involvement in rheumatoid arthritis and its relationship to induced oxidative stress. Rheumatology (Oxford). 42:1234-41; 2003.

3. Abdollahi M.; Fooladian F.; Emami B.; Zafari K.; Bahreini-Moghadam A. Protection by sildenafil and theophylline of lead acetate-induced oxidative stress in rat submandibular gland and saliva. Hum. Exp. Toxicol. 22:587-92; 2003.

4. de la Cal C.; Lomniczi A.; Mohn C. E.; De Laurentiis A.; Casal M.; Chiarenza A.; Paz D.; McCann S. M.; Rettori V.; Elverdin J. C. Decrease in salivary secretion by radiation mediated by nitric oxide and prostaglandins. Neuroimmunomodulation. 13:19-27; 2006.

5. Tsukahara H. Biomarkers for oxidative stress: clinical application in pediatric medicine. Curr. Med. Chem. 14:339-51; 2007.

6. Aharoni-Simon M.; Reifen R.; Tirosh O. ROS-production-mediated activation of AP-1 but not NFאB inhibits glutamate-induced HT4 neuronal cell death. Antioxid. Redox. Signal. 8:1339-49; 2006.

7. Nakabeppu Y. Regulation of intracellular localization of human MTH1, OGG1, and MYH proteins for repair of oxidative DNA damage. Prog. Nucleic Acid Res. Mol. Biol. 68:75-94; 2001.

8. Yasui K.; Baba A. Therapeutic potential of superoxide dismutase (SOD) for resolution 
of inflammation. Inflamm. Res. 55:359-63; 2006.

9. Ryter S. W.; Choi A. M. Heme oxygenase-1: redox regulation of a stress protein in lung and cell culture models. Antioxid. Redox. Signal. 7:80-91; 2005.

10. Shukla N.; Maher J.; Masters J.; Angelini G. D.; Jeremy J. Y. Does oxidative stress change ceruloplasmin from a protective to a vasculopathic factor? Atherosclerosis. 187:238-50; 2006.

11. Yung L. M.; Leunq F. P.; Yao X.; Chen Z. Y.; Huang Y. Reactive oxygen species in vascular wall. Cardiovasc. Hematol. Disord. Drug Targets. 6:1-19; 2006.

12. Aliyev A.; Chen S. G.; Seyidova D.; Smith M. A.; Perry G.; de la Torre J.; Aliev G. Mitochondria DNA deletions in atherosclerotic hypoperfused brain microvessels as a primary target for the development of Alzheimer's disease. J. Neurol. Sci. 15: 285-92; 2005.

13. Raval J.; Lyman S.; Nitta T.; Mohuczy D.; Lemasters J. J.; Kim J. S.; Behrns K. E. Basal reactive oxygen species determine the susceptibility to apoptosis in cirrhotic hepatocytes. Free Radic. Biol. Med. 41:1645-54; 2006.

14. Verzola D.; Bertolotto M. B.; Villaggio B.; Ottonello L.; Dallegri F.; Salvatore F.; Berruti V.; Gandolfo M. T.; Garibotto G.; Deferrari G. Oxidative stress mediates apoptotic changes induced by hyperglycemia in human tubular kidney cells. J. Am. Soc. Nephrol. 15:S85-7; 2004. 
15. Nauseef W. M. Assembly of the phagocyte NADPH oxidase. Histochem. Cell Biol. 122:277-91; 2004.

16. Cheng G.; Cao Z.; Xu X.; van Meir E. G.; Lambeth J. D. Homologs of gp91phox: cloning and tissue expression of Nox3, Nox4, and Nox5. Gene. 16:131-40; 2001.

17. Rokutan K.; Kawahara T.; Kuwano Y.; Tominaga K.; Sekiyama A.; Teshima-Kondo S. NADPH oxidases in the gastrointestinal tract: a potential role of Nox 1 in innate immune response and carcinogenesis. Antioxid. Redox Signal. 8:1573-82; 2006.

18. Banfi B.; Malgrange B.; Knisz J.; Steger K.; Dubois-Dauphin M.; Krause KH. NOX3, a superoxide-generating NADPH oxidase of the inner ear. J. Biol. Chem. 279:46065-72; 2004.

19. Shiose A.; Kuroda J.; Tsuruya K.; Hirai M.; Hirakata H.; Naito S.; Hattori M.; Sakaki Y.; Sumimoto H. A novel superoxide-producing NAD $(\mathrm{P}) \mathrm{H}$ oxidase in kidney. J. Biol. Chem. 276:1417-23; 2001.

20. Ago T.; Kitazono T.; Ooboshi H.; Iyama T.; Han Y. H.; Takada J.; Wakisaka M.; Ibayashi S.; Utsumi H.; Iida M. Nox4 as the major catalytic component of an endothelial NAD(P)H oxidase. Circulation. 109:227-33; 2004.

21. Banfi B.; Molnar G.; Maturana A.; Steger K.; Hegedus B.; Demaurex N.; Krause K. H. A $\mathrm{Ca}(2+)$-activated NADPH oxidase in testis, spleen, and lymph nodes. J. Biol. Chem. 276:37594-601; 2001. 
22. Azuma M.; Tamatani T.; Kasai Y.; Sato M. Immortalization of normal human salivary gland cells with duct-, myoepithelial-, acinar-, or squamous phenotype by transfection with SV40 ori-mutant deoxyribonucleic acid. Lab. Invest. 69:24-42; 1993.

23. Kim A.; Oberley L. W.; Oberley T. D. Induction of apoptosis by adenovirus-mediated manganese superoxide dismutase overexpression in SV-40-transformed human fibroblasts. Free Radic. Biol. Med. 39:1128-41; 2005.

24. Yamamoto T.; Hsu S.; Lewis J.; Wataha J.; Dickinson D.; Singh B.; Bollag W. B.; Lockwood P.; Ueta E.; Osaki T.; Schuster G. Green tea polyphenol causes differential oxidative environments in tumor versus normal epithelial cells. J. Pharmacol. Exp. Ther. 307:230-6; 2003.

25. Konings A. W.; Faber H.; Cotteleer F.; Vissink A.; Coppes R. P. Secondary radiation damage as the main cause for unexpected volume effects: a histopathologic study of the parotid gland. Int. J. Radiat. Oncol. Biol. Phys. 64:98-105; 2006.

26. Nagler R. M. The enigmatic mechanism of irradiation-induced damage to the major salivary glands. Oral Dis. 8:141-6; 2002.

27. Donko A.; Peterfi Z.; Sum A.; Leto T.; Geiszt M. Dual oxidases. Philos. Trans. R. Soc. Lond. B. Biol. Sci. 360:2301-8; 2005.

28. Kuwano Y.; Kawahara T.; Yamamoto H.; Teshima-Kondo S.; Tominaga K.; Masuda K.; Kishi K.; Morita K.; Rokutan K. Interferon-gamma activates transcription of NADPH 
oxidase 1 gene and upregulates production of superoxide anion by human large intestinal epithelial cells. Am. J. Physiol. Cell Physiol. 290:C433-43; 2006.

29. Pleskova M.; Beck K. F.; Behrens M. H.; Huwiler A.; Fichtlscherer B.; Wingerter O.; Brandes R. P.; Mulsch A.; Pfeilschifter J. Nitric oxide down-regulates the expression of the catalytic NADPH oxidase subunit Nox1 in rat renal mesangial cells. FASEB J. 20:139-41; 2006.

30. Geiszt M.; Lekstrom K.; Brenner S.; Hewitt S. M.; Dana R.; Malech H. L.; Leto T. L. $\mathrm{NAD}(\mathrm{P}) \mathrm{H}$ oxidase 1 , a product of differentiated colon epithelial cells, can partially replace glycoprotein 91phox in the regulated production of superoxide by phagocytes. J. Immunol. 171:299-306; 2003.

31. Kawahara T.; Kuwano Y.; Teshima-Kondo S.; Takeya R.; Sumimoto H.; Kishi K.; Tsunawaki S.; Hirayama T.; Rokutan K. Role of nicotinamide adenine dinucleotide phosphate oxidase 1 in oxidative burst response to Toll-like receptor 5 signaling in large intestinal epithelial cells. J. Immunol. 172:3051-8; 2004.

32. Wingler K.; Wunsch S.; Kreutz R.; Rothermund L.; Paul M.; Schmidt H. H. Upregulation of the vascular $\mathrm{NAD}(\mathrm{P}) \mathrm{H}$-oxidase isoforms Nox1 and Nox4 by the renin-angiotensin system in vitro and in vivo. Free Radic. Biol. Med. 31:1456-64; 2001

33. Katsuyama M.; Fan C.; Arakawa N.; Nishinaka T.; Miyagishi M.; Taira K.; 
Yabe-Nishimura C. Essential role of ATF-1 in induction of NOX1, a catalytic subunit of NADPH oxidase: involvement of mitochondrial respiratory chain. Biochem. J. 386:255-61; 2005.

34. Desouki M. M.; Kulawiec M.; Bansal S.; Das G. M.; Singh K. K. Cross talk between mitochondria and superoxide generating NADPH oxidase in breast and ovarian tumors. Cancer Biol. Ther. 4:1367-73; 2005.

35. Kawahara T.; Kohjima M.; Kuwano Y.; Mino H.; Teshima-Kondo S.; Takeya R.; Tsunawaki S.; Wada A.; Sumimoto H.; Rokutan K. Helicobacter pylori lipopolysaccharide activates Rac1 and transcription of NADPH oxidase Nox1 and its organizer NOXO1 in guinea pig gastric mucosal cells. Am. J. Physiol. Cell Physiol. 288:C450-7; 2005.

36. Takeya R.; Ueno N.; Kami K.; Taura M.; Kohjima M.; Izaki T.; Nunoi H.; Sumimoto H. Novel human homologues of p47phox and p67phox participate in activation of superoxide-producing NADPH oxidases. J. Biol. Chem. 278:25234-46; 2003.

37. Banfi B.; Clark R. A.; Steger K.; Krause K. H. Two novel proteins activate superoxide generation by the NADPH oxidase NOX1. J. Biol. Chem. 278:3510-3; 2003.

38. Ueno N.; Takeya R.; Miyano K.; Kikuchi H.; Sumimoto H. The NADPH oxidase Nox3 constitutively produces superoxide in a p22phox-dependent manner: its regulation by oxidase organizers and activators. J. Biol. Chem. 280:23328-39; 2005. 
39. Sumimoto H.; Miyano K.; Takeya R. Molecular composition and regulation of the Nox family NAD(P)H oxidases. Biochem. Biophys. Res. Commun. 338:677-86; 2005.

40. O'Connell A. C.; Redman R. S.; Evans R. L.; Ambudkar I. S. Radiation-induced progressive decrease in fluid secretion in rat submandibular glands is related to decreased acinar volume and not impaired calcium signaling. Radiat. Res. 151:150-8; 1999. 


\section{Figure legends}

Figure 1. Influence of $\gamma$-ray irradiation on cell proliferation, apoptosis induction and ROS generation in NS-SV-AC and NS-SV-DC cells.

(A) NS-SV-AC and NS-SV-DC cells were irradiated at doses of 5 or 10 Gy and cell proliferation was determined by MTT assay at $48 \mathrm{~h}$. (B, C) NS-SV-AC and NS-SV-DC cells were incubated in the presence or absence of NAC or apocynin for $1 \mathrm{~h}$ and were exposed to 10 Gy of $\gamma$-rays. Then, apoptosis induction (B) and ROS generation (C) were analyzed at the indicated times as described in Materials and Methods. Results are the mean \pm standard deviation of triplicate determinations from a representative experiment which was undertaken three times. *: $\mathrm{p}<0.05$ compared to non-irradiated cells and $\dagger: \mathrm{p}<0.05$ compared to $\gamma$-ray-treated cells, by Mann-Whitney's U-test.

Figure 2. Expression of the Nox family in NS-SV-AC and NS-SV-DC cells.

(A) The expression of Nox1 5 and Duox 1/2 mRNA on NS-SV-AC and NS-SV-DC cells was determined by RT-PCR before and after 10 Gy irradiation $(30 \mathrm{~min})$. Results are representative of three separate experiments. (B) The expression of Nox 1 mRNA and protein on NS-SV-AC and NS-SV-DC cells was analyzed by real-time PCR and Western blotting, respectively, before and after 10 Gy irradiation (real-time PCR; 30 min, Western blotting; 2 h). Results are representative of three separate experiments and each bar 
indicates the mean \pm standard deviation of triplicate determinations. $\quad *$ : $p<0.05$ compared to non-irradiated cells, by Mann-Whitney's U-test.

Figure 3. Influence of knockdown of the Nox family on $\gamma$-ray-induced ROS production and apoptosis induction in NS-SV-AC cells.

NS-SV-AC cells were transiently transfected with each siRNA and cultured for $24 \mathrm{~h}$. After exposure the cells 10 Gy of $\gamma$-rays, intracellular ROS levels (A), Nox1 mRNA expression (B) and apoptosis induction $(\mathrm{C})$ were determined at the indicated times. Resuls are the mean \pm standard deviation of triplicate determinations from a representative experiment which was undertaken three times. $*$ : $p<0.05$ compared to non-irradiated cells and $\uparrow: p<0.05$ compared to control siRNA-transfected cells, by Mann-Whitney's U-test.

Figure 4. Expression and activity of SOD and catalase in NS-SV-AC and NS-SV-DC cells. NS-SV-AC and NS-SV-DC cells were irradiated at a dose of 10 Gy irradiation. Then, the expression of Mn-SOD (A) and catalase (C) and activitiy of SOD (B) and catalase (D) were determined at the indicated times. Results are representative of three separate experiments and each bar indicates the mean \pm standard deviation of triplicate determinations. $\quad *: p<0.05$ compared to non-irradiated cells and $\dagger: \mathrm{p}<0.05$ compared to NS-SV-DC cells, by Mann-Whitney's U-test. 


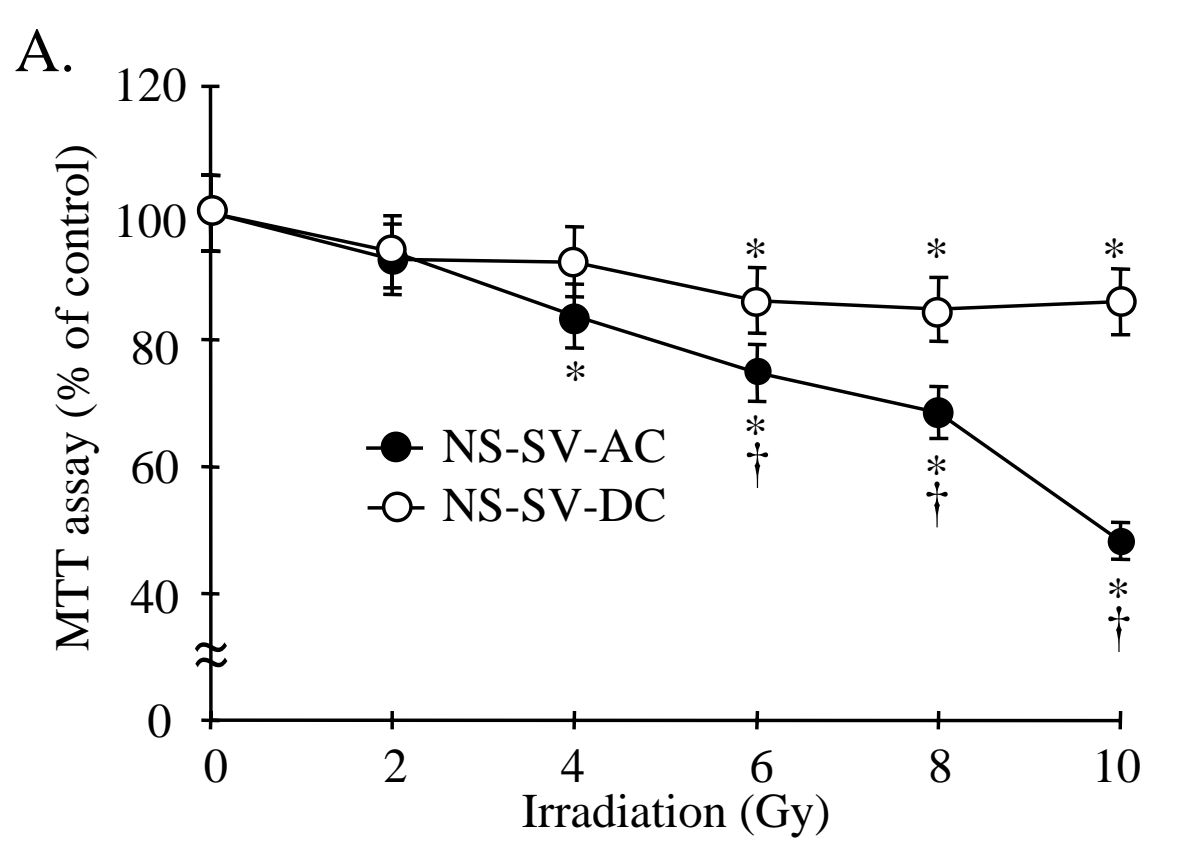

B.

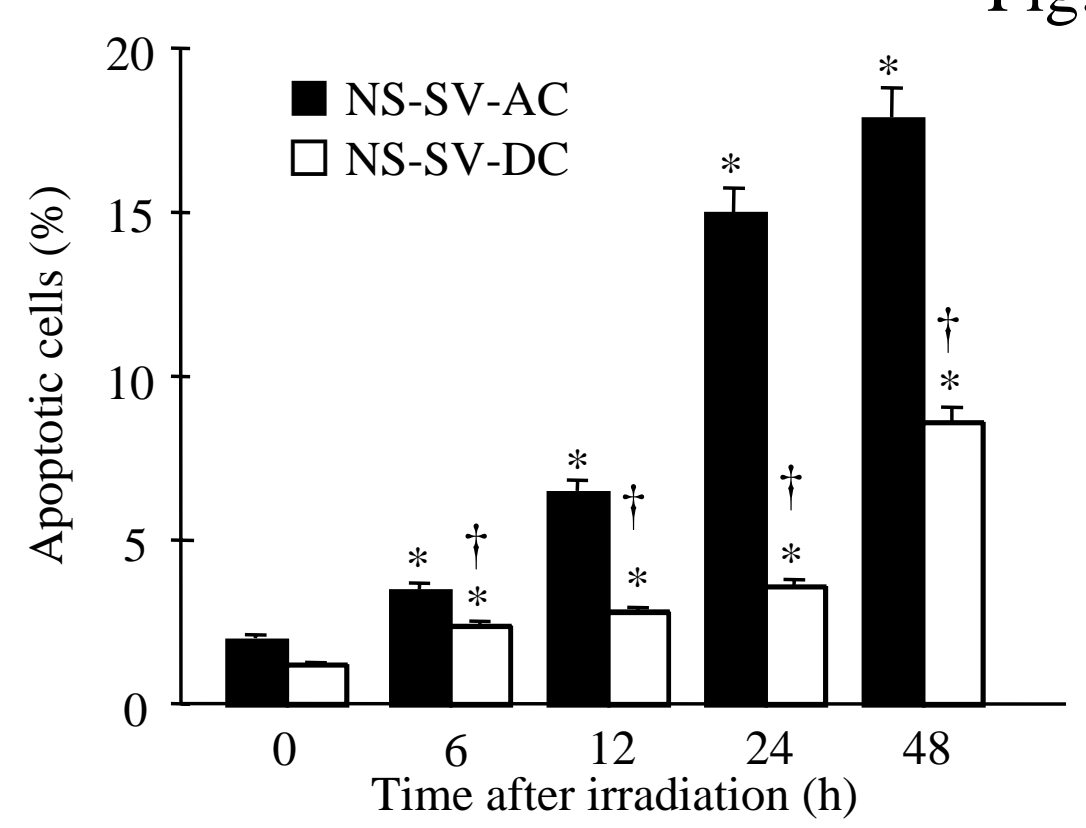

C.

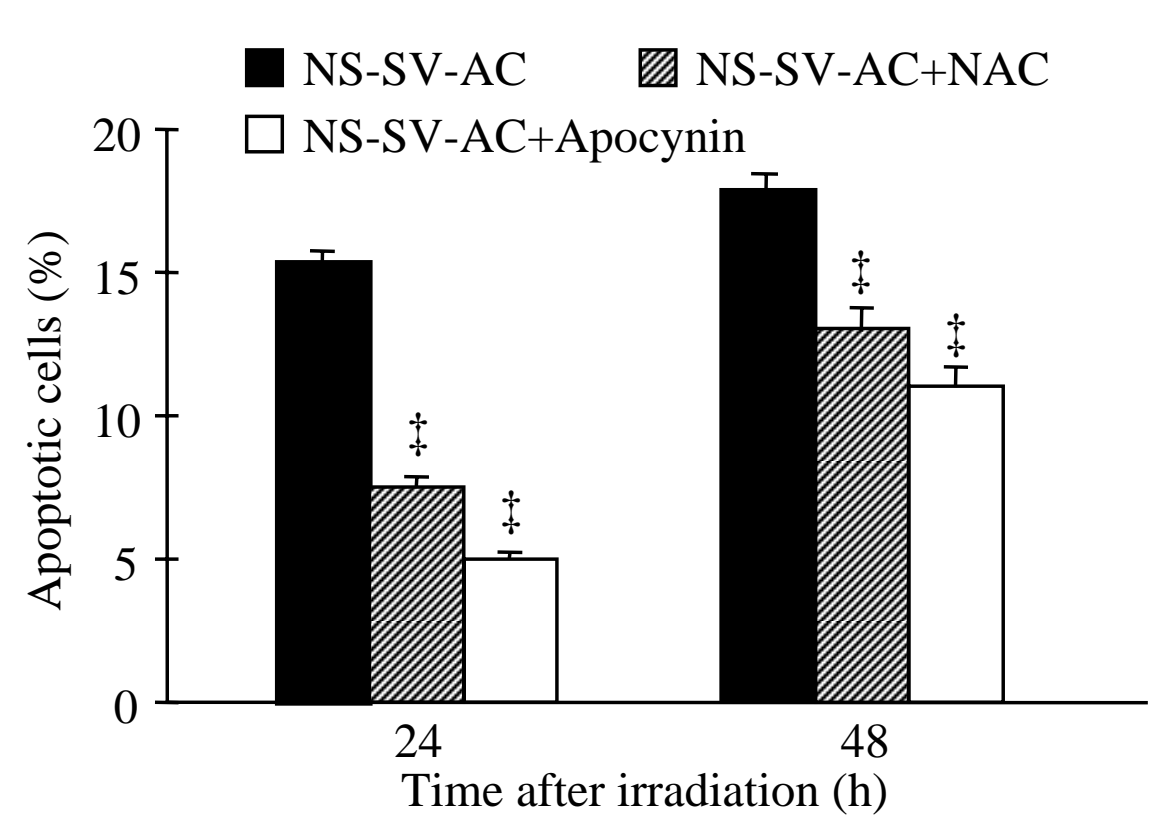

Fig. 1

D. $\quad 70 \rightarrow-\square$ NS-SV-AC $\triangle$ NS-SV-AC-NAC
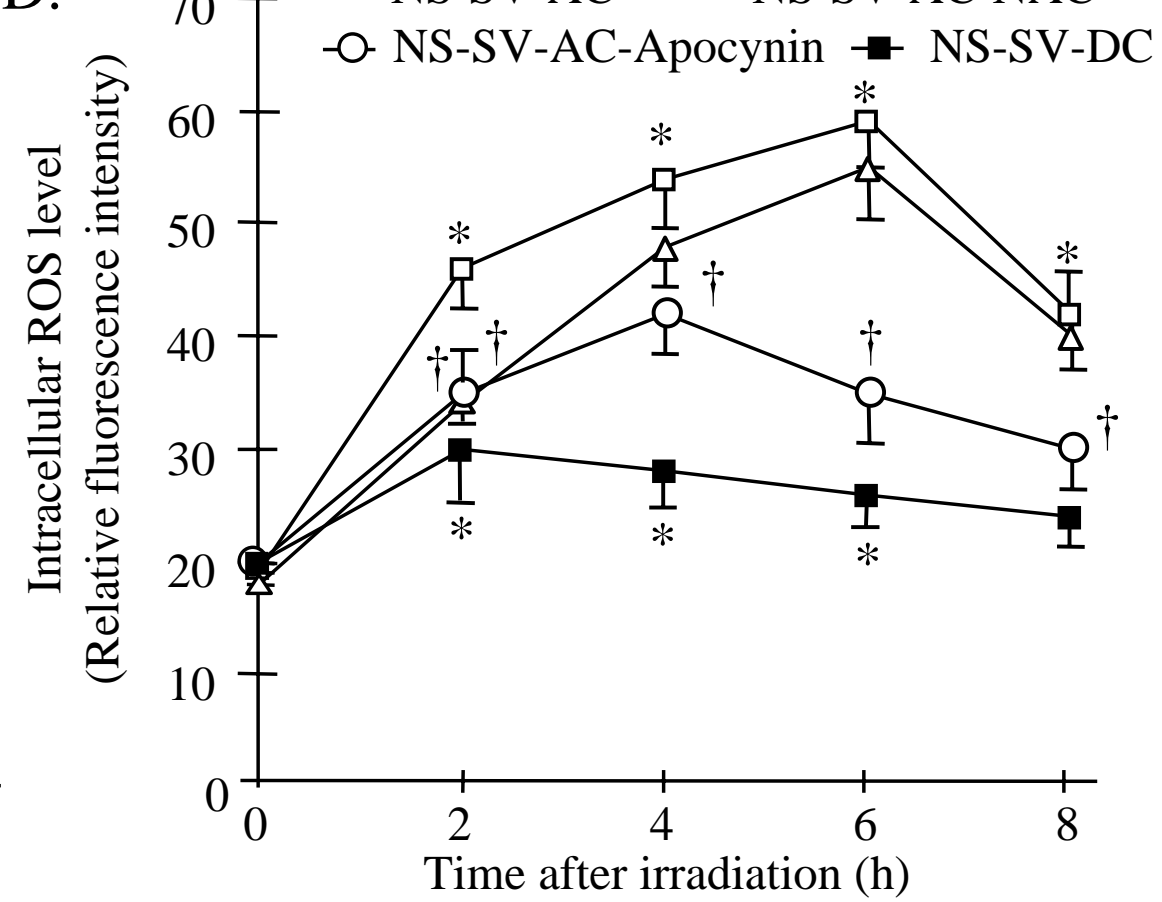
Fig. 2

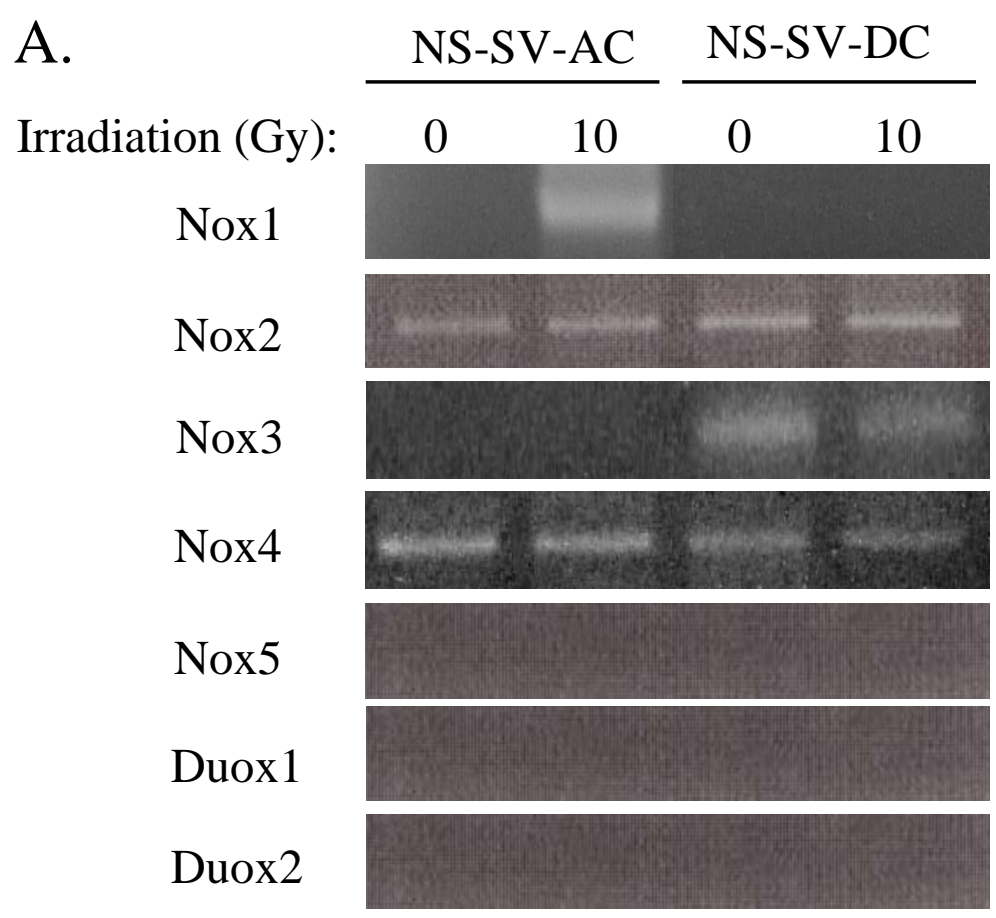

B.

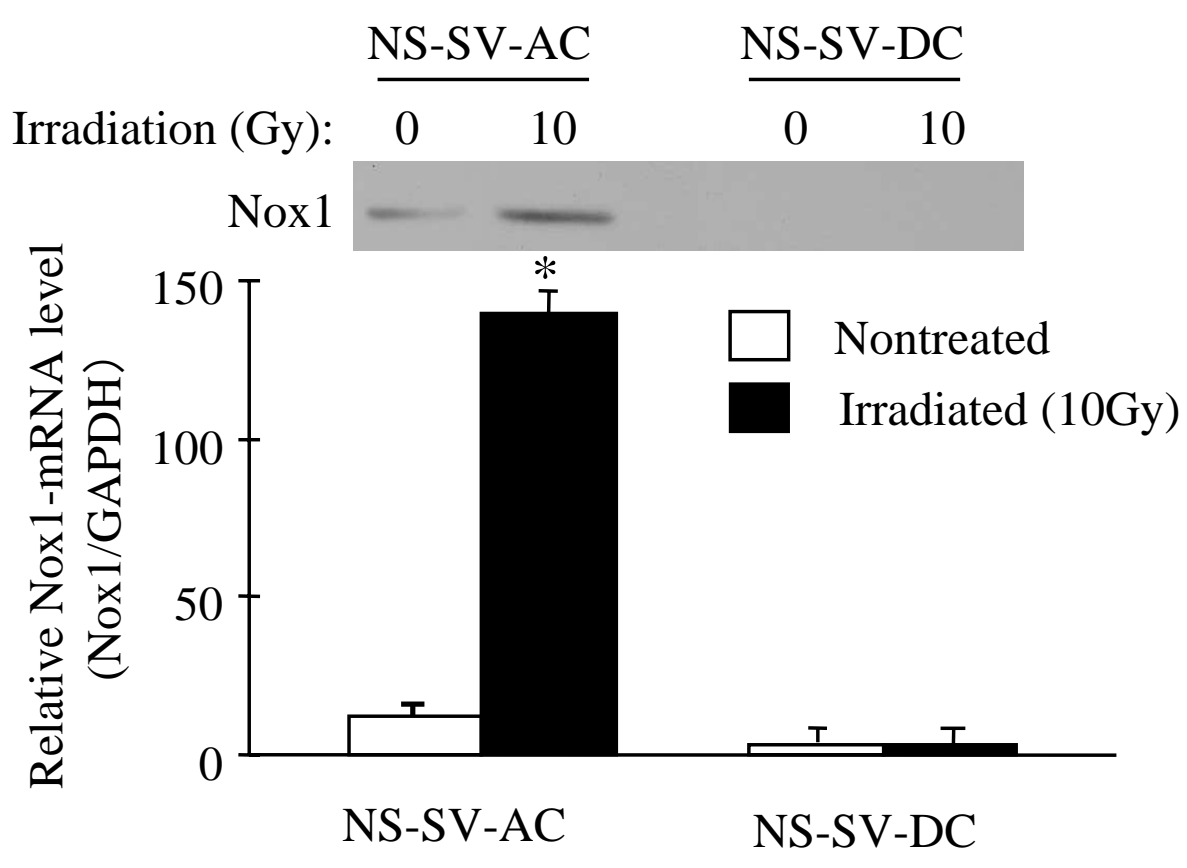


Fig. 3

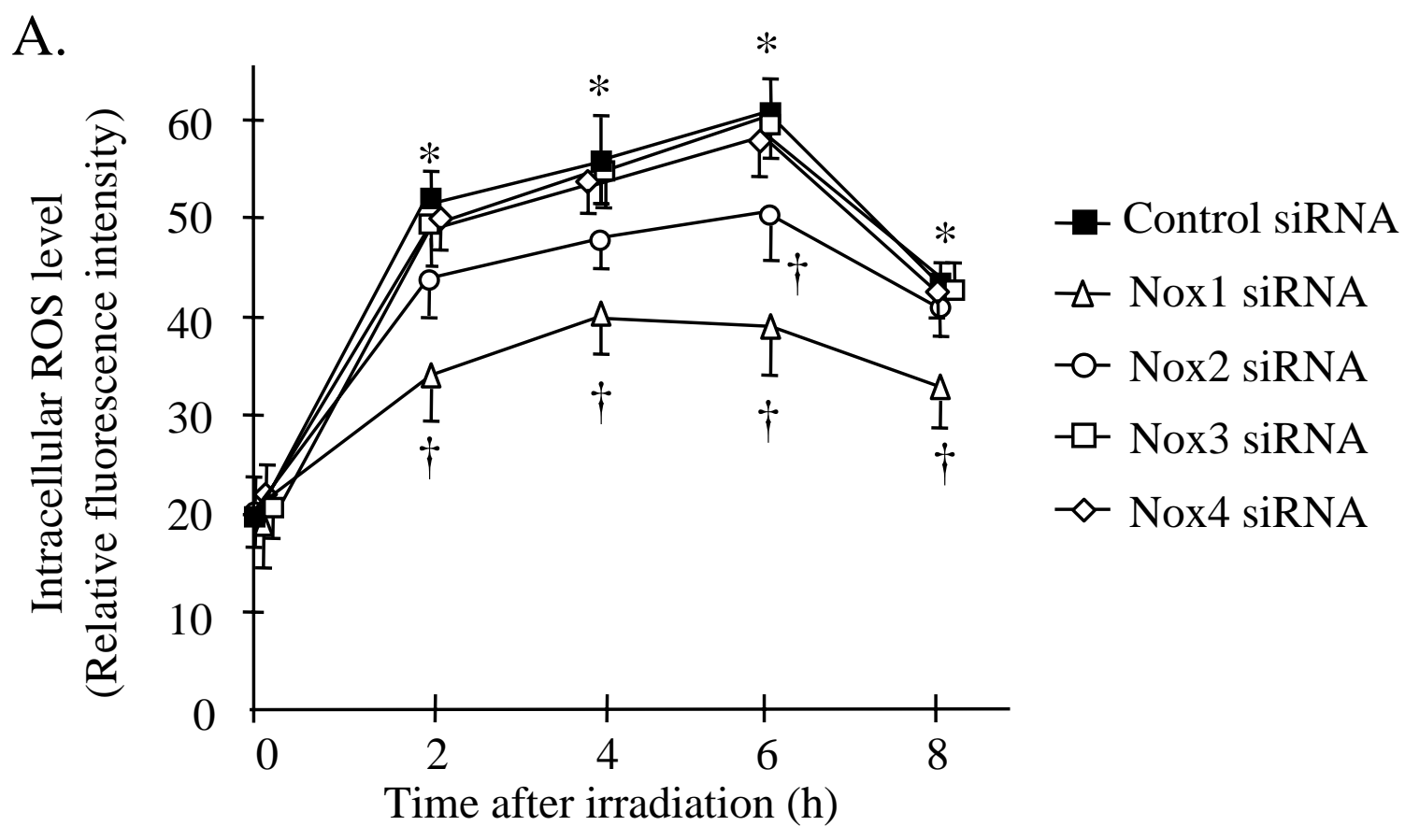

B.

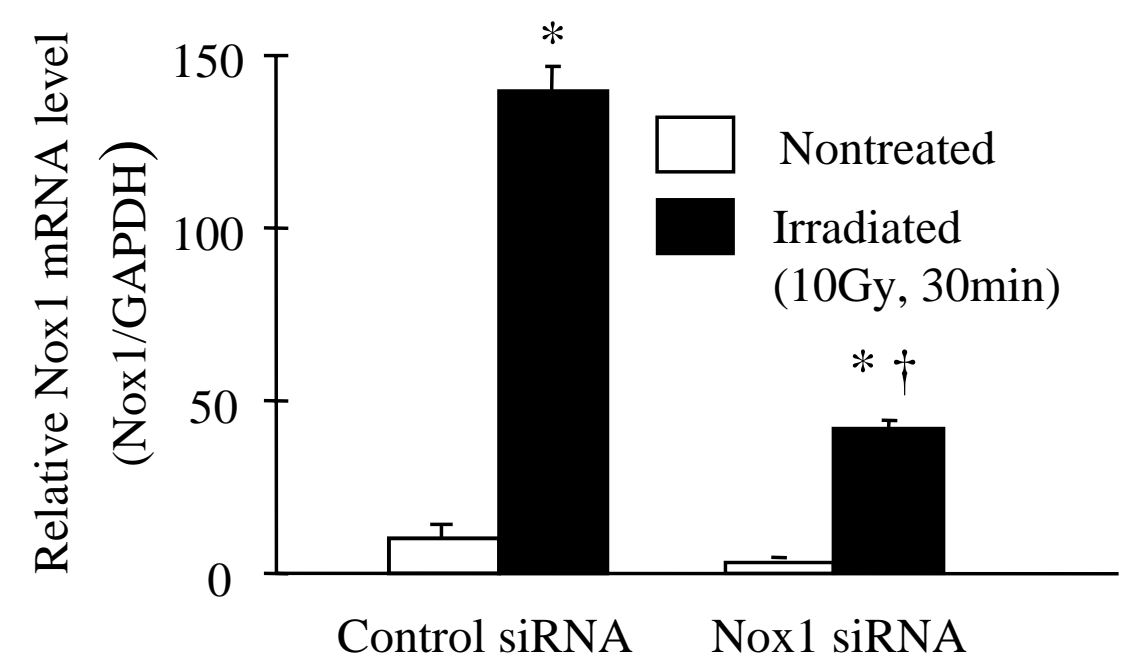

C.

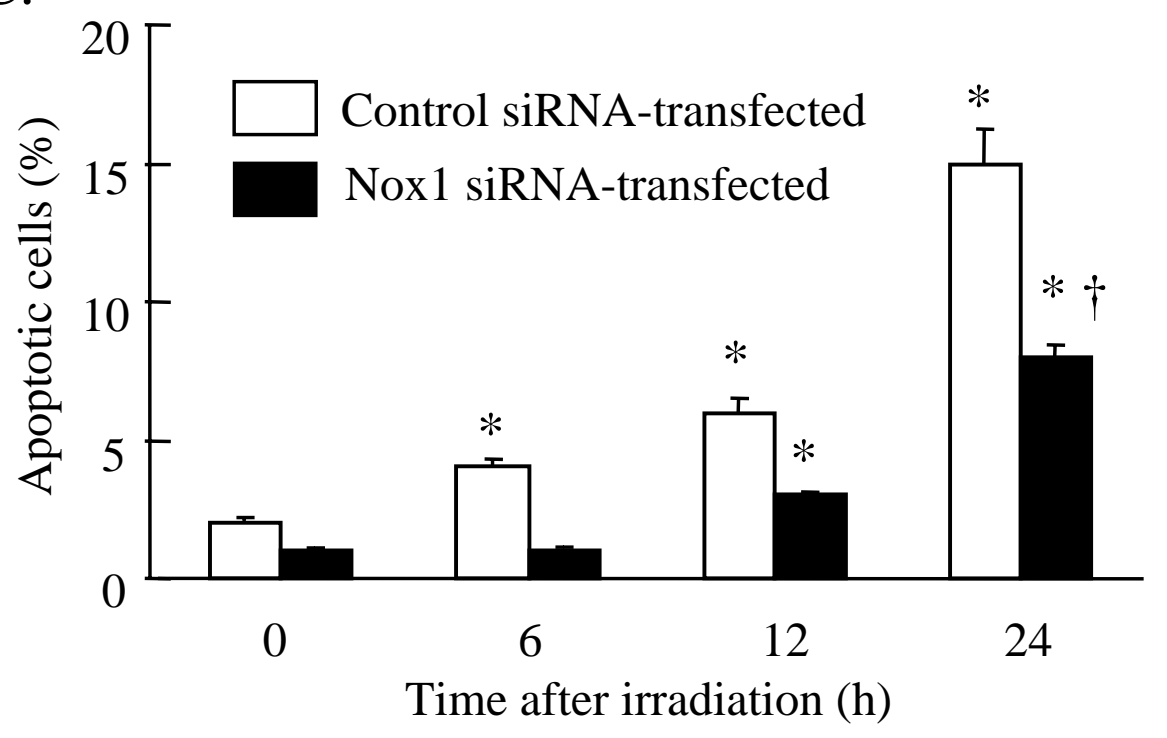


Fig. 4

A.

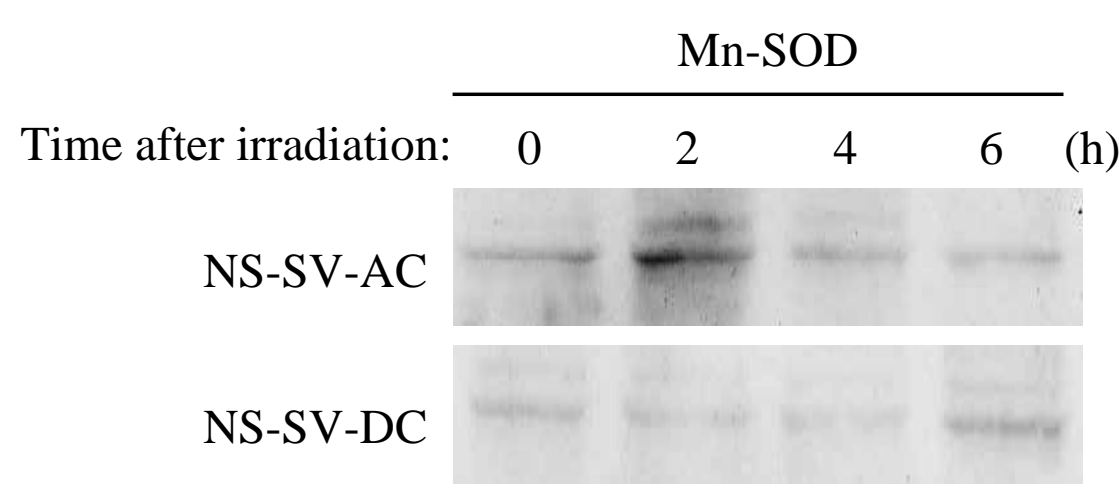

C.

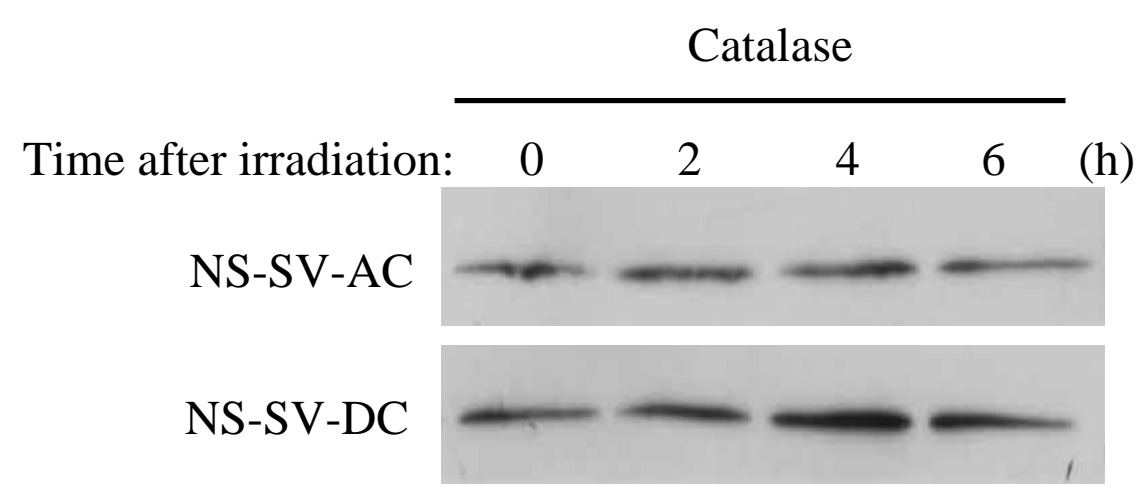

B.

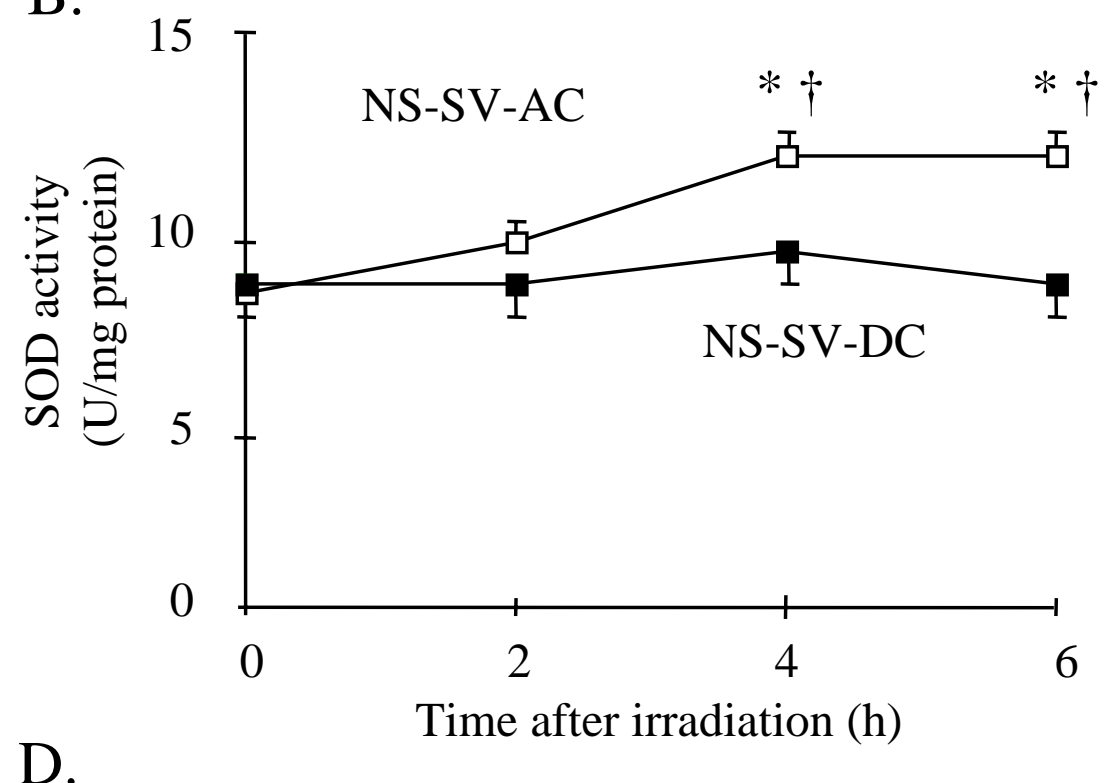

D.

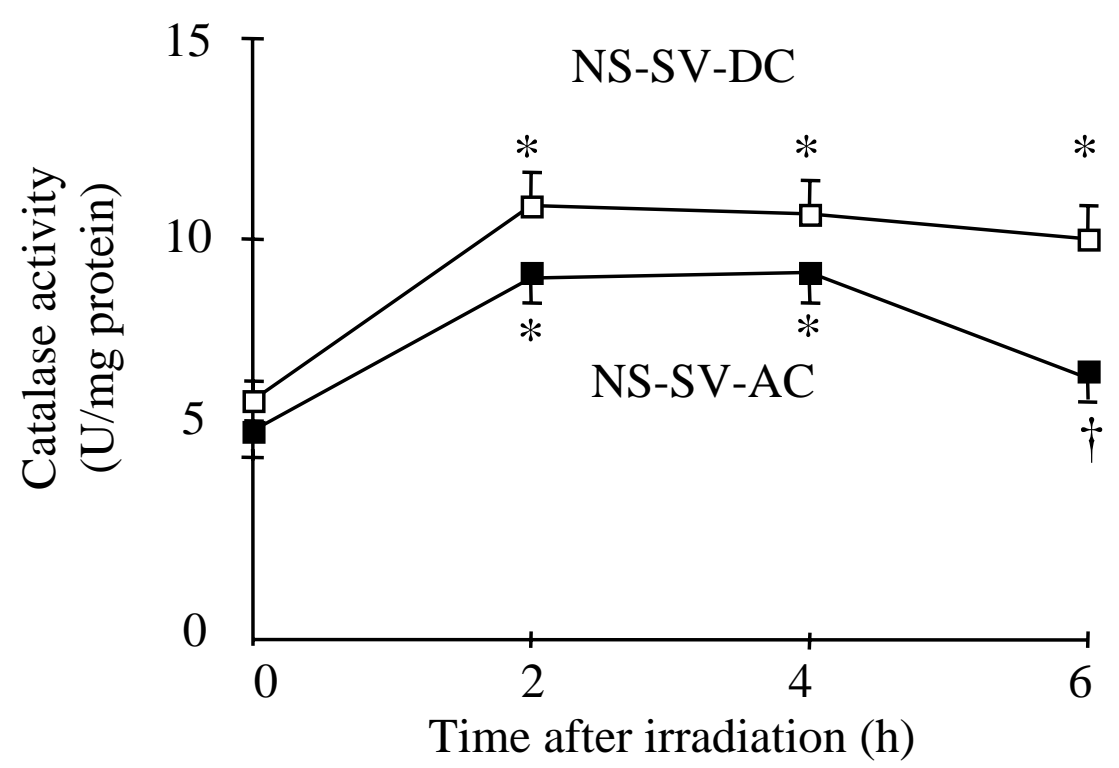

